\title{
Knowledge, Attitudes and Practices Regarding HIV Amongst Women of Childbearing Age in the NYANGA Province, Gabon
}

\section{Augustin Mouinga-Ondémé ( $\nabla$ ondeme@yahoo.fr)}

Centre International de Recherches Medicales de Franceville https://orcid.org/0000-0002-3143-1060

\section{Sydney Maghendji-Nzondo}

Universite des Sciences de la Sante de Libreville

Julie Buekens

Medical Care Development International

Jéordy-Dimitri Engone-Ondo

Centre International de Recherches Medicales de Franceville

Roméo Karl Imboumy-Limoukou

Centre International de Recherches Medicales de Franceville

\section{Pater Noster Sir-Ondo-Enguier}

Centre International de Recherches Medicales de Franceville

Julie Niemczura de Carvalho

Medical Care Development International

Nathalie Pernelle Tsafack-Tegomo

Centre International de Recherches Medicales de Franceville

Jean-Bernard Lékana-Douki

Centre International de Recherches Medicales de Franceville

\section{Research}

Keywords: HIV, PMTCT, Prevention, traditional beliefs, witchcraft, Nyanga, Gabon

Posted Date: March 15th, 2021

DOI: https://doi.org/10.21203/rs.3.rs-300204/v1

License: @) (i) This work is licensed under a Creative Commons Attribution 4.0 International License. Read Full License 


\section{Abstract}

Background: The seroprevalence of HIV in Gabon is $4.1 \%$. This rate varies among its nine provinces and is estimated at $4.2 \%$ in the province of Nyanga. This variance is believed to be the result of a lack of information and beliefs regarding HIV transmission and prevention. There are currently scarce epidemiological data from this region of Gabon. We assessed the knowledge, attitudes and practices of women of childbearing age from Nyanga province towards HIV.

Methods: A 13-day cross-sectional descriptive study of 631 women aged 15 to 49 years was conducted within the five departments of the province to assess their knowledge and attitudes about HIV, with particular emphasis on motherto-child HIV transmission (MTCT). Household recruitment of participants was conducted and information was collected by means of a questionnaire. Correct answers were considered as indicating a basic knowledge of the topic assessed.

Results: Around $90 \%$ of women (570/631) were of childbearing age but not pregnant during the survey, with a mean age of 28 years. Also, 10\% (61/631) were pregnant. Among surveyed women, 99.2\% had heard of HIV/AIDS and $81.8 \%$ knew at least one screening site for HIV. More than $83.6 \%$ knew that MTCT could occur during pregnancy, and 76.5\% knew about transmission during breastfeeding. In addition, 86.5\% knew that HIV couldn't be transmitted through sharing food with an infected person. Similarly, $68.8 \%$ answered that HIV transmission cannot occur through mosquito bites. However, $45.8 \%$ of women said that HIV could be transmitted by witchcraft. For $81.6 \%$ of participants, HIV could be prevented by having a single monogamous sexual partner and protected sex. Seventy percent of the women were aware of antiretroviral therapy. More than $80 \%$ of the participants indicated that they had been screened overall, and $77.3 \%$ said that they had been offered HIV screening services during antenatal visits.

Conclusions: Almost all women of childbearing age in Nyanga had heard of HIV, yet about half of them had poor knowledge of its modes of transmission. It is therefore imperative to carry out awareness campaigns in conjunction with HIV testing services to better understand the current prevalence of HIV infection in the region.

\section{Background}

The Human Immunodeficiency Virus (HIV) which causes the Acquired Immunodeficiency Syndrome (AIDS) pandemic is still a public health concern. In 2019, 38 million people were living with HIV [1] and 1.7 million were newly infected. Two thirds of these new infections are registered in Africa, the most infected continent, where 25.6 million people are living with HIV/AIDS. In Gabon, the last Demographic and Health Survey (DHS) reported the infection in 63,000 people and the prevalence was estimated at 4.1\% [2]. According to the DHS, this prevalence seems to be the consequence of a lack of knowledge about the disease, the different routes of transmission and prevention.

Of the two HIVs, HIV-1 is the most endemic. The most well-known modes of transmission in the world are: unprotected sexual intercourse, blood transfusion, and mother-to-child [3, 4]. HIV-1 consists of 4 established groups, these are groups $\mathrm{M}, \mathrm{N}, \mathrm{O}$ and $\mathrm{P}[5]$. The group $\mathrm{M}$ is responsible for a majority of infections around the world and is regularly described in Gabon under different circulating recombinant forms (CRFs) [6, 7]. HIV infection could be reduced if people used barrier methods such as condoms, having a single sexual partner or choosing abstinence. More specifically, if women have unprotected sexual intercourse with other partners beside their primary partner(s) during pregnancy or if their partners had other partners, they could be infected with HIV and they have the chance to transmit the virus to their infants [8,9]. As well, women treated early in their pregnancy could decrease mother-to-child (MTC) transmission of HIV [10]. As recommended by the World Health Organization (WHO) and the Joint United 
Nations Programme on HIV/AIDS [11], prevention of new HIV transmission should be considered an important action in the strategy of fight HIV/AIDS [12]. HIV testing and immediate treatment could limit the dissemination of the pandemic $[13,14]$. A key approach could be the use of the rapid diagnostic tests (RDTs), which facilitate screening of HIV infection due to their many advantages [15]. Indeed, RDTs have a very low price per test, can be stored at room temperature, do not need complex infrastructure, can be performed in a very few steps, and results can be read visually [16]. Due to the absence of a cure for HIV, antiretroviral therapy (ART) continues to expand in resource-limited countries as the primary care and prevention approach, as well as to contribute to the control of viral replication and decreased HIV transmission, particularly from mother-to-child. Thus, RDTs could provide an opportunity to achieve the UNAIDS' 95-95-95 goals by 2030: $95 \%$ of all people living with HIV will know their status, $95 \%$ of all people diagnosed will receive sustained antiretroviral therapy (ART), and 95\% of all people receiving ART will have viral suppression [17].

Gabon, a West Central African country, is divided into nine provinces, and Nyanga is located in the south-west of the country, home to 52,854 people. In Nyanga province, HIV seroprevalence is $4.2 \%$, one of the highest rate by province and relatively higher than the national seroprevalence [2]. This variance is hypothesized to be the result of a lack of information regarding HIV transmission and prevention. There are currently scarce epidemiological data from this region of Gabon concerning knowledge, attitudes and practices in the fight against HIV/AIDS.

We conducted a cross-sectional household survey to inform the "Improved Integrated Maternal and Neonatal Survival through Malaria and HIV/AIDS Prevention in Gabon Project." Our goal was to assess the knowledge, attitudes and practices of women of childbearing age from Nyanga province towards HIV, with particular emphasis on mother-tochild transmission of HIV. The selected approach was to assess some of the possible misconceptions concerning the modes of transmission of HIV among the study population. Thus, this study was organized to obtain a baseline for planned interventions to improve service delivery for the prevention of mother-to-child transmission of HIV that were undertaken by the non-governmental organization (NGO) Medical Care Development International (MCDI) in Nyanga province following the study.

\section{Materials And Methods}

\section{Study sites and Population}

This is a 13-day cross-sectional, descriptive, and analytical epidemiological study conducted in March 2018 among women residing in five of six departmental capitals of the Nyanga province, including Mayumba, Moabi, Mabanda, Moulengui-Binza, and Tchibanga (Figure 1) as described previously [18]. The most important natural resources of Nyanga are oil and gas. Also, this province is covered with rainforest and hosts the Moukalaba-Doudou National Park with prized species like elephants, small monkeys, gorillas and chimpanzees. The study population matched the following preselected inclusion criteria: 1) resided within the study site during the study period; 2) signed the consent form; and 3) were women of childbearing age, defined as being 15 to 49 years old. All women aged 15 to 49 years old in the households surveyed were included in the study and information was collected by means of a questionnaire. The study was approved by the Gabonese National Ethics Committee (Nº01/PR/SG/CNE/2018).

\section{Development of a Questionnaire}

The data collection questionnaire was generated based on the Demographic and Health Survey (DHS) and various questionnaires from similar studies conducted previously [19-21]. The questionnaire can be accessed here (Additional file 1). Two sections consisted of: Socio-demographic characteristics of the study population across questions like 
age, pregnancy status and professional status; and Knowledge about HIV transmission and prevention. Specific questions were asked to women of childbearing age regarding understanding and possible common misconceptions about HIV transmission ("by mosquito bite?","by food?","by witchcraft?"), mother-to-child transmission ("during pregnancy?," "during delivery?," "during breastfeeding?"). Similarly, prevention knowledge was assessed with two other questions: HIV transmission can be prevented "by having a single sexual partner?" and "by using a condom during sexual activity?". Correct answers from participants were considered as having a basic knowledge of HIV.

\section{Data collection}

The approach applied in this study was the same jointly defined for the malaria study we published previously [18]. Before starting interviews, we selected all households with women of childbearing age. Then a convenience sample of households was selected for inclusion in the study; all neighborhoods of the departmental capitals were represented. If no member from an identified household was willing to participate, the teams approached the next house on the list until reaching household willing to participate in the study. The survey was performed by ten teams of three persons deployed across the five cities. The sample size in each departmental capital was calculated based on probability proportional to size.

\section{Data analysis}

Statistical analysis was carried out with Epi-info version 3.5.3 (2005, CDC, Atlanta, USA) and STATA version 14 (Stata Corp, College Station, USA). Age was expressed as the mean and standard deviation. The age variable was transformed into a categorical variable. The Chi-squared test was used to compare categorical variables. Values of $p<0.05$ were considered to indicate a statistically significant difference.

\section{Results}

\section{Characteristics of the study population}

A total of 631 women were interviewed for this study, 90\% (570/631) were of childbearing age but not pregnant at the time of the survey and 10\% (61/631) were pregnant; the mean age of overall participants was 28 years old.

Information about occupation was collected for 620 women, most of whom were unemployed $(n=327 ; 52.7 \%)$, employed $(n=173 ; 27.9 \%)$ and students $(n=120 ; 19.4 \%)$. Table 1 summarizes the demographic characteristics of the study population. 
Table 1

Socio-demographic characteristics of the study population

\begin{tabular}{|c|c|c|c|c|c|c|}
\hline \multirow[t]{2}{*}{ Parameters } & \multicolumn{6}{|c|}{ Cities (n/N (\%)) } \\
\hline & Mabanda & Mayumba & Moabi & $\begin{array}{l}\text { Moulengui- } \\
\text { Binza }\end{array}$ & Tchibanga & Total \\
\hline \multicolumn{7}{|l|}{ Categories } \\
\hline $\begin{array}{l}\text { Women of childbearing age not } \\
\text { currently pregnant }\end{array}$ & $\begin{array}{l}100 \% \\
(49 / 49)\end{array}$ & $\begin{array}{l}85 \% \\
(63 / 74)\end{array}$ & $\begin{array}{l}87 \% \\
(65 / 75)\end{array}$ & $\begin{array}{l}92 \% \\
(34 / 37)\end{array}$ & $\begin{array}{l}91 \% \\
(359 / 396)\end{array}$ & 570 \\
\hline Pregant women & $0 \%(0 / 49)$ & $\begin{array}{l}15 \% \\
(11 / 74)\end{array}$ & $\begin{array}{l}13 \% \\
(10 / 75)\end{array}$ & $8 \%(3 / 37)$ & $\begin{array}{l}9 \% \\
(37 / 396)\end{array}$ & 61 \\
\hline Total & 49 & 74 & 75 & 37 & 396 & 631 \\
\hline \multicolumn{7}{|l|}{ Women occupation $(\mathrm{N}=620)$} \\
\hline Student & $\begin{array}{l}9.5 \% \\
(4 / 42)\end{array}$ & $\begin{array}{l}1.4 \% \\
(1 / 72)\end{array}$ & $\begin{array}{l}36.0 \% \\
(27 / 75)\end{array}$ & $\begin{array}{l}16.2 \% \\
(6 / 37)\end{array}$ & $\begin{array}{l}20.8 \% \\
(82 / 394)\end{array}$ & 120 \\
\hline Employed & $\begin{array}{l}38.1 \% \\
(16 / 42)\end{array}$ & $\begin{array}{l}30.5 \% \\
(22 / 72)\end{array}$ & $\begin{array}{l}33.3 \% \\
(25 / 75)\end{array}$ & $\begin{array}{l}48.7 \% \\
(18 / 37)\end{array}$ & $\begin{array}{l}23.4 \% \\
(92 / 394)\end{array}$ & 173 \\
\hline Unemployed & $\begin{array}{l}52.4 \% \\
(22 / 42)\end{array}$ & $\begin{array}{l}68.1 \% \\
(49 / 72)\end{array}$ & $\begin{array}{l}30.7 \% \\
(23 / 75)\end{array}$ & $\begin{array}{l}35.1 \% \\
(13 / 37)\end{array}$ & $\begin{array}{l}55.8 \% \\
(220 / 394)\end{array}$ & 327 \\
\hline
\end{tabular}

\section{HIV/AIDS-related knowledge on transmission and prevention}

Results about knowledge indicated that 99.2\% (621/626) women had heard of HIV/AIDS and 81.8\% (508/621) knew of at least one screening site for HIV including hospitals and other health facilities $(n=222 ; 39.6 \%)$, and the Ambulatory Treatment Centre (CTA) where HIV-1 patients receive ART in Tchibanga ( $n=325 ; 57.8 \%$ ). In regards to HIV transmission, $83.6 \%$ of women knew that mother-to-child HIV transmission can occur during pregnancy; $85.4 \%$ (527/617) knew that it could occur during delivery and $78 \%$ agreed that a mother could transmit the virus through breastfeeding. Also, more than $85.4 \%$ (531/614) of participants knew that HIV could not be transmitted through sharing food with an infected person. Similarly, 68.8\% (422/613) answered that HIV transmission cannot occur through mosquito bites. On the topic of HIV prevention, $81.6 \%$ of participants indicated that HIV can be prevented by having a single sexual partner and protected sex. However, some misconceptions were highlighted among $45.8 \%$ (280/612) of women who said that HIV could be transmitted by witchcraft. All HIV/AIDS-related knowledge, transmission and prevention are summarized in Table 2. 
Table 2

Women's knowledge of HIV transmission and prevention

\begin{tabular}{|c|c|c|c|c|c|c|c|c|}
\hline & \multicolumn{4}{|c|}{ HIV transmission (\% (n)) } & \multicolumn{4}{|c|}{ HIV Prevention (\% (n)) } \\
\hline & $\begin{array}{l}\text { By } \\
\text { mosquito } \\
\text { bite }\end{array}$ & $\begin{array}{l}\text { By } \\
\text { food }\end{array}$ & $\begin{array}{l}\text { By } \\
\text { witchcraft }\end{array}$ & $\begin{array}{l}\text { Mother-to- } \\
\text { child } \\
\text { during } \\
\text { pregnancy }\end{array}$ & $\begin{array}{l}\text { Mother-to- } \\
\text { child during } \\
\text { breastfeeding }\end{array}$ & $\begin{array}{l}\text { Mother- } \\
\text { to-child } \\
\text { during } \\
\text { delivery }\end{array}$ & $\begin{array}{l}\text { Having } \\
\text { a } \\
\text { single } \\
\text { sexual } \\
\text { partner }\end{array}$ & $\begin{array}{l}\text { Using } \\
\text { condoms } \\
\text { during } \\
\text { sexual } \\
\text { intercourse }\end{array}$ \\
\hline \multirow[t]{2}{*}{ No } & $69 \%$ & $86.5 \%$ & $47.2 \%$ & $8.3 \%$ & $11.0 \%$ & $5.2 \%$ & $12.8 \%$ & $11.5 \%$ \\
\hline & (422) & (531) & (289) & (51) & (68) & (32) & (77) & (67) \\
\hline \multirow[t]{2}{*}{ Unknown } & $7,3 \%$ & $2.1 \%$ & $7.0 \%$ & $8.1 \%$ & $12.5 \%$ & $9.4 \%$ & $5.6 \%$ & $4.0 \%$ \\
\hline & (45) & (13) & (45) & (50) & (77) & (58) & (34) & (23) \\
\hline \multirow[t]{2}{*}{ Yes } & $23.8 \%$ & $11.40 \%$ & $45.8 \%$ & $83.6 \%$ & $76.5 \%$ & $85.4 \%$ & $81.6 \%$ & $84.5 \%$ \\
\hline & (146) & (70) & (280) & (517) & (471) & (527) & (491) & (492) \\
\hline Total & 613 & 614 & 612 & 618 & 616 & 617 & 602 & 582 \\
\hline
\end{tabular}

\section{Information and practices against HIV/AIDS}

The results showed that more than $70.7 \%$ of women were informed about practices against HIV/AIDS and were aware that medicines exist that infected pregnant women can take to reduce the risk of MTCT (antiretroviral therapy). In addition, $91 \%$ said it is possible that a healthy-looking person could be infected (Table 3 ). Also, $84.5 \%$ answered that using a condom during sexual intercourse can prevent HIV infection (Table 2). More than $80 \%$ of the participants indicated that they had ever been screened for HIV and $77.3 \%$ said that they had been offered HIV screening services during antenatal visits (Table 3 ). Regarding practices, $75 \%$ of women declared using good practices to prevent HIV/AIDS. In addition to being tested during antenatal visits (77.3\%), they also planned to follow up to obtain the results of their medical examinations (83.9\%). We found that only $63.4 \%$ of women received advice from medical staff after receiving results (Table 4$)$. 
Table 3

Women's knowledge level about HIV in Nyanga province

\begin{tabular}{|lllllll|}
\hline & $\begin{array}{l}\text { Existence } \\
\text { of ART* } \\
\text { for PMTCT }\end{array}$ & $\begin{array}{l}\text { Healthy- } \\
\text { looking } \\
\text { person }\end{array}$ & $\begin{array}{l}\text { Children } \\
\text { infected } \\
\text { by } \\
\text { mothers }\end{array}$ & $\begin{array}{l}\text { Existence of } \\
\text { measures } \\
\text { against HIV / } \\
\text { AlDS }\end{array}$ & $\begin{array}{l}\text { Agreed to } \\
\text { be tested } \\
\text { for } \\
\text { HIV/AIDS }\end{array}$ & $\begin{array}{l}\text { Invitation to be tested for } \\
\text { HIV/AIDS during the last } \\
\text { pregnancy }\end{array}$ \\
\hline Yes & $70.7 \%$ & $90.9 \%$ & $54.0 \%$ & $61.9 \%$ & $82.5 \%$ & $77.3 \%$ \\
& $(437)$ & $(558)$ & $(275)$ & $(312)$ & $(414)$ & $(388)$ \\
\hline No & $13.6 \%$ & $7.0 \%$ & $38.3 \%$ & $30.2 \%$ & $16.1 \%$ & $17.7 \%$ \\
\hline Unknown & $15.7 \%$ & $2.1 \%$ & $7.7 \%$ & $7.9 \%$ & $(81)$ & $(89)$ \\
& $(84)$ & $(43)$ & $(195)$ & $(152)$ & $1.39 \%$ & $5 \%$ \\
\hline
\end{tabular}

Table 4

Selected HIV testing practices among women in Nyanga province

\begin{tabular}{|llll|}
\hline HIV testing & $\begin{array}{l}\text { Results collected } \\
\text { by the patient }\end{array}$ & Advice from medical staff after the results \\
\hline Yes & $81.7 \%$ & $83.9 \%$ & $63.4 \%$ \\
& $(370)$ & $(374)$ & $(279)$ \\
No & $17.9 \%$ & $15.5 \%$ & $35.5 \%$ \\
& $(81)$ & $(69)$ & $(156)$ \\
Unknown & $0.4 \%$ & $0.6 \%$ & $1.1 \%$ \\
& $(2)$ & $(3)$ & $(5)$ \\
\hline Total & 453 & 446 & 440 \\
\hline
\end{tabular}

\section{Discussion}

The current cross-sectional descriptive study was conducted to assess the HIV/AIDS-related knowledge, attitudes and practices among 631 women aged 15 to 49 years old, with a particular emphasis on mother-to-child transmission of HIV. We found that most women from Nyanga province have a good level of knowledge of mother-to-child transmission, prevention and practices against HIV/AIDS. Unfortunately, some participants revealed misconceptions about the AIDS pandemic.

According to the last Gabonese Demographic and Health Survey (GDHS) [2], 99\% of women in the general population had heard of HIV/AIDS. This rate was not formally estimated in the Nyanga province during the same survey. In our study, $99.2 \%$ of women were informed about HIV/AIDS, suggesting that well-organized awareness campaigns contribute to the dissemination of proper HIV/AIDS comprehensive knowledge in this province since the last GDHS. 
Also, it would seem that information from different communication channels was delivered to the population. Indeed, during interviews, participants confirmed obtaining information on HIV/AIDS from medical staff, as well as from media outlets such as television, radio, and social media. The fact that $81.8 \%$ of participants knew of at least one screening site for HIV could positively impact their families and society as a whole. We believe that a consequence of increased knowledge could probably be the decrease of the HIV seroprevalence in this province; the next GDHS will confirm this hypothesis.

Our results demonstrate a good level of knowledge on prevention of mother-to-child transmission of HIV (PMTCT) among participants during pregnancy, delivery and while breastfeeding. These findings suggest that awareness campaigns in Nyanga province have also focused on these modes of transmission. The percentage of knowledge of transmission during breastfeeding is similar (76\%) to the one found during the 2012 GDHS [2]. The early description of the transmission of HIV from mother-to-child after the onset of the epidemic [22], and the joint action between the provincial multi-sectoral committee against AIDS and the PMTCT program in Gabon could explain the high rates of good knowledge about MTC transmission. In addition to knowledge of the modes of transmission, use of antiretroviral therapy (ART) is a solution to prevent MTCT by reducing the viral load and improving the quality of life of HIV-infected persons [23, 24]. Furthermore, ART became available in 2001 in the country, and was made available free of cost starting in 2011. In our study, 70.7\% of women were aware of ART, a result likely related to several good practices against HIV/AIDS collected from participants, like HIV counseling and testing (HCT). Nevertheless, higher numbers of respondents declared being tested during antenatal visits (81.7\%) and going back to collect the results of their medical examinations (83.9\%). Other studies corroborate our findings and have indicated that persons who were aware of ART were more likely to use HCT services $[19,25,26]$.

Counseling is related to the prevention of HIV transmission [27]; by answering that HIV could be contracted from a healthy-looking person, $91 \%$ of women of childbearing age confirmed that they could identify HIV's real modes of transmission [28-30]. Kwaganzo et al. published previously that "HIV counselling and testing services provide information on HIV transmission prevention" [27].

In spite of this good knowledge, misconceptions were also identified during the study. Through our results, we confirm that HIV/AIDS knowledge can be affected by the overall socio-cultural context where, for example, some modes of transmission can be known, while more culturally sensitive modes of transmission may not be as widely recognized, which may contribute to false perceptions of risk [31]. During our investigation, some beliefs held about HIV transmission modes included witchcraft and mosquito bites. A large part of participants, 45.8\% (280/612), claimed that HIV could be transmitted by witchcraft. This idea is widespread in several Sub-Saharan African countries and constitutes a major cultural feature [32]. Previous studies conducted in Ghana, Congo, Zambia, Zimbabwe, etc. concluded that witchcraft played a key role in the social fabric of most African societies [32, 33] and may influence prevention behaviors. Other beliefs of HIV transmission have been noted among $23.8 \%(146 / 613)$ of women who answered that HIV transmission occurred through mosquito bites. This misconception was highlighted in other studies; $13.6 \%$ among dental patients at a Nigerian teaching hospital, 59.5\% among university students in Xinjiang, China and $48.2 \%$ among secondary school adolescents in Nigeria [3, 23, 34]. Also, the difference in educational status among participants and the fact that so many of them live in rural areas could have influenced their knowledge. Finally, as Gabon is a hyperendemic zone for malaria [35], some participants could believe that HIV transmission occurs by mosquito bites. The risk is the persistence of such beliefs that may reduce or distort prevention behaviors [32], and beliefs are can be resistant to change and entrenched in people's behavior with the consequence being that they are taught by one generation to the next [36].

\section{Limitations of the study}


This survey encountered limitations, mainly due to information bias. A particular methodological limitation may have been the use of a closed survey instrument, which asked participants to agree or disagree with an affirmation about HIV. The response options of Yes, No, and I Don't Know may have led some respondents to answer "Yes" to concepts that they lacked previous familiarity with, in order to seem knowledgeable or to please the investigator. The affirmations used in the survey were based on common beliefs about HIV found in the literature. It might have been more informative from a socio-anthropological perspective to use an open-ended survey or other qualitative research method in order to take stock of novel beliefs on sources of HIV infection that are unique to Nyanga province; however, doing so would have rendered quantitative data analysis impossible. Another limitation was the lack of answers to all of the survey questions. Indeed, a large amount of data were missing, leading to differences in the numbers of women for each parameter studied (transmission by mosquito bite, by food, by witchcraft, awareness of the existence of ART, having ever been tested for HIV/AIDS, etc.). The lack of experience of our investigators during interviews, despite an initial training on the survey methodology, may have contributed to this difference.

\section{Conclusion}

This study reported that women of childbearing age (15-49 years) from Nyanga province in Gabon have a good level of knowledge, including of mother-to-child transmission, prevention and attitudes against HIV/AIDS. The misconceptions highlighted raise a challenge to achieve the UNAIDS' 95-95-95 goals set for 2030 in this relatively remote part of Gabon. The "Improved Integrated Maternal and Neonatal Survival through Malaria and HIV/AIDS Prevention Project" in Gabon, which was funded by Noble Energy to begin interventions after this study, was designed with these findings in mind to help improve correct knowledge of HIV/AIDS and limit the spread of the virus, particularly through PMTCT.

\section{Abbreviations}

HIV/AIDS: Human immunodeficiency virus/Acquired immunodeficiency syndrome; PMTCT: Prevention of mother-tochild HIV transmission; UNAIDS: United Nations programme on HIVI/AIDS; WHO: World Health Organization; CRFs: Circulating recombinant forms; ART: antiretroviral therapy; ATC : Ambulatory Treatment Centre ; HCT: HIV counseling and testing; NGO: Non-government organization; MCDI: Medical Care Development International; GDHS: Gabonese Demographic and Health Survey; CIRMF: Centre International de Recherches Médicales de Franceville.

\section{Declarations}

\section{Ethics approval and consent to participate}

The study was approved by the Gabonese National Ethics Committee (N001/PR/SG/CNE/2018).

\section{Consent for publication}

Not applicable

\section{Availability of data and materials}

Not applicable

\section{Competing interests}

The authors declare that they have no competing interests. 


\section{Funding}

This work was supported by Noble Energy Gabon Ltd. and Woodside Energy (Gabon) Pty Ltd , through the Improved Integrated Maternal and Neonatal Survival Malaria and HIV/AIDS Prevention project, financed with the Gabonese Ministry of Petroleum and Hydrocarbon's Local Community Development Fund, and implemented by Medical Care Development International from 2017-2019.

\section{Authors' contributions}

All authors read and approved the final manuscript. AMO, JBLD, JNDC and JB participated in the conception and design of the study. AMO, MNS and JDEO participated in the interpretation of results. AMO drafted and coordinated manuscript writing and wrote the first draft. AMO, JBLD, RKIL, MNS, NPTT, PNSOE, contributed to the acquisition of data in the field.

\section{Acknowledgements}

We thank sincerely all participants to this study and all investigators who done interviews. We would like to acknowledge the MCDI (Medical Care Development International, European and Developing Countries Clinical Trials Partnership) and the CIRMF (Centre International de Recherches Médicales de Franceville) for this partnership. Finally, we thank Dr Thierry Tsoumbou for providing the Nyanga map, and John Pollock for critiquing this manuscript.

\section{References}

1. UNAIDS, GLOBAL AIDS MONITORING. Available from: https://www.unaids.org/en/resources/documents/2020/unaids-data 2020.

2. EDSG, Enquête Démographique et de Santé du Gabon 2012: Rapport de synthèse. 2012, DGS et ICF International Calverton, MD.

3. Opeodu, O.I. and T.J. Ogunrinde, MODE OF TRANSMISSION OF HIVIAIDS: PERCEPTION OF DENTAL PATIENTS IN A NIGERIAN TEACHING HOSPITAL. J West Afr Coll Surg, 2015. 5(1): p. 1-19.

4. Nelson, C.S., G.G.A. Fouda, and S.R. Permar, Pediatric HIV-1 Acquisition and Lifelong Consequences of Infant Infection. Curr Immunol Rev, 2019. 15(1): p. 131-138.

5. Plantier, J.C., et al., A new human immunodeficiency virus derived from gorillas. Nat Med, 2009. 15(8): p. 871-2.

6. Liégeois, F., et al., Virological failure rates and HIV-1 drug resistance patterns in patients on first-line antiretroviral treatment in semirural and rural Gabon. J Int AIDS Soc, 2012. 15(2): p. 17985.

7. Ndjoyi-Mbiguino, A., et al., Performance of rapid HIV-1/HIV-2 INSTI on plasma and capillary blood for serological diagnosis of non B subtypes and circulating recombinant forms of HIV-1 in Gabon. Med Mal Infect, 2015. 45(8): p. 339-40.

8. Drake, A.L., et al., Incident HIV during pregnancy and postpartum and risk of mother-to-child HIV transmission: a systematic review and meta-analysis. PLoS Med, 2014. 11(2): p. e1001608.

9. Mushamiri, I., et al., Optimizing PMTCT efforts by repeat HIV testing during antenatal and perinatal care in resource-limited settings: A longitudinal assessment of HIV seroconversion. PLoS One, 2020. 15(5): p. e0233396.

10. Blanche, S., et al., Growth in HIV-1-exposed but uninfected infants treated with lopinavir-ritonavir versus lamivudine: a secondary analysis of the ANRS 12174 trial. Lancet HIV, 2019. 6(5): p. e307-e314.

11. UNAIDS, The gap report. Geneva: UNAIDS; 2014. https://www.unaids.org/en/resources/documents/2014/20140716_UNAIDS_gap_report, J.U.N.P.o. HIV/AIDS, 
Editor. 2014.

12. WHO, WHO: Global health sector strategy on VIH, 2016-2021. available from:

https://www.who.int/hiv/strategy2016-2021/ghss-hiv/en/. 2016, World Health Organization.

13. Granich, R.M., et al., Universal voluntary HIV testing with immediate antiretroviral therapy as a strategy for elimination of HIV transmission: a mathematical model. Lancet, 2009. 373(9657): p. 48-57.

14. Havlir, D., et al., What do the Universal Test and Treat trials tell us about the path to HIV epidemic control? J Int AIDS Soc, 2020. 23(2): p. e25455.

15. Mourez, T., et al., HIV rapid screening tests and self-tests: Be aware of differences in performance and cautious of vendors. EBioMedicine, 2018. 37: p. 382-391.

16. Kosack, C.S., A.L. Page, and P.R. Klatser, A guide to aid the selection of diagnostic tests. Bull World Health Organ, 2017. 95(9): p. 639-645.

17. UNAIDS. Understanding Fast-Track: Accelerating Action to End the AIDS Epidemic by 2030. 2015 [cited 2021 02/25/2021]; Available from:

https://www.unaids.org/sites/default/files/media_asset/201506_JC2743_Understanding_FastTrack_en.pdf

18. Imboumy-Limoukou, R.K., et al., Malaria in children and women of childbearing age: infection prevalence, knowledge and use of malaria prevention tools in the province of Nyanga, Gabon. Malar J, 2020. 19(1): p. 387.

19. Chimoyi, L., et al., HIV-related knowledge, perceptions, attitudes, and utilisation of HIV counselling and testing: a venue-based intercept commuter population survey in the inner city of Johannesburg, South Africa. Glob Health Action, 2015. 8: p. 26950.

20. Mall, S., et al., Changing patterns in HIV/AIDS stigma and uptake of voluntary counselling and testing services: the results of two consecutive community surveys conducted in the Western Cape, South Africa. AIDS Care, 2013. 25(2): p. 194-201.

21. Shamu, S., et al., Knowledge, attitudes and practices of young adults towards HIV prevention: an analysis of baseline data from a community-based HIV prevention intervention study in two high HIV burden districts, South Africa. BMC Public Health, 2020. 20(1): p. 1249.

22. Oleske, J.M. and A.B. Minnefor, Acquired immune deficiency syndrome in children. Pediatr Infect Dis, 1983. 2(2): p. 85-6.

23. Agu, I.C., et al., Misconceptions about transmission, symptoms and prevention of HIV/AIDS among adolescents in Ebonyi state, South-east Nigeria. BMC Res Notes, 2020. 13(1): p. 244.

24. Mintsa-Ndong, A., et al., Mother-to-child HIV-transmission prevention programs in a sub-Saharan African setting: The Gabonese experience. Int J STD AIDS, 2018. 29(3): p. 221-226.

25. Venkatesh, K.K., et al., Who gets tested for HIV in a South African urban township? Implications for test and treat and gender-based prevention interventions. J Acquir Immune Defic Syndr, 2011. 56(2): p. 151-65.

26. Tran, B.X., et al., Depression and Quality of Life among Patients Living with HIV/AIDS in the Era of Universal Treatment Access in Vietnam. Int J Environ Res Public Health, 2018. 15(12).

27. Kwagonza, L., et al., Comprehensive knowledge of HIV prevention among fishing communities of Lake Kyoga, Uganda, 2013. BMC Public Health, 2020. 20(1): p. 29.

28. Pisani, E., et al., Back to basics in HIV prevention: focus on exposure. Bmj, 2003. 326(7403): p. 1384-7.

29. Gouws, E., et al., Short term estimates of adult HIV incidence by mode of transmission: Kenya and Thailand as examples. Sex Transm Infect, 2006. 82 Suppl 3(Suppl 3): p. iii51-55.

30. Yavuz, B., et al., Pharmaceutical Approaches to HIV Treatment and Prevention. Adv Ther (Weinh), 2018. 1(6). 
31. Mumtaz, G.R., et al., Characterising HIV/AIDS knowledge and attitudes in the Middle East and North Africa: Systematic review and data synthesis. Glob Public Health, 2020. 15(2): p. 275-298.

32. Tenkorang, E.Y., et al., Superstition, witchcraft and HIV prevention in sub-Saharan Africa: the case of Ghana. Cult Health Sex, 2011. 13(9): p. 1001-14.

33. Pearson, S. and P. Makadzange, Help-seeking behaviour for sexual-health concerns: a qualitative study of men in Zimbabwe. Cult Health Sex, 2008. 10(4): p. 361-76.

34. Bamise, O.F., C.T. Bamise, and M.A. Adedigba, Knowledge of HIV/AIDS among secondary school adolescents in Osun state, Nigeria. Niger J Clin Pract, 2011. 14(3): p. 338-44.

35. Boumbanda Koyo, C.S., et al., High Circulation of Malaria and Low Prevalence of Bacteremia in Febrile and Afebrile Children in Northeastern Gabon. Am J Trop Med Hyg, 2020. 102(1): p. 121-129.

36. Amuyunzu-Nyamongo, M., et al., Putting on a brave face: the experiences of women living with HIV and AIDS in informal settlements of Nairobi, Kenya. AIDS Care, 2007. 19 Suppl 1: p. S25-34.

\section{Figures}

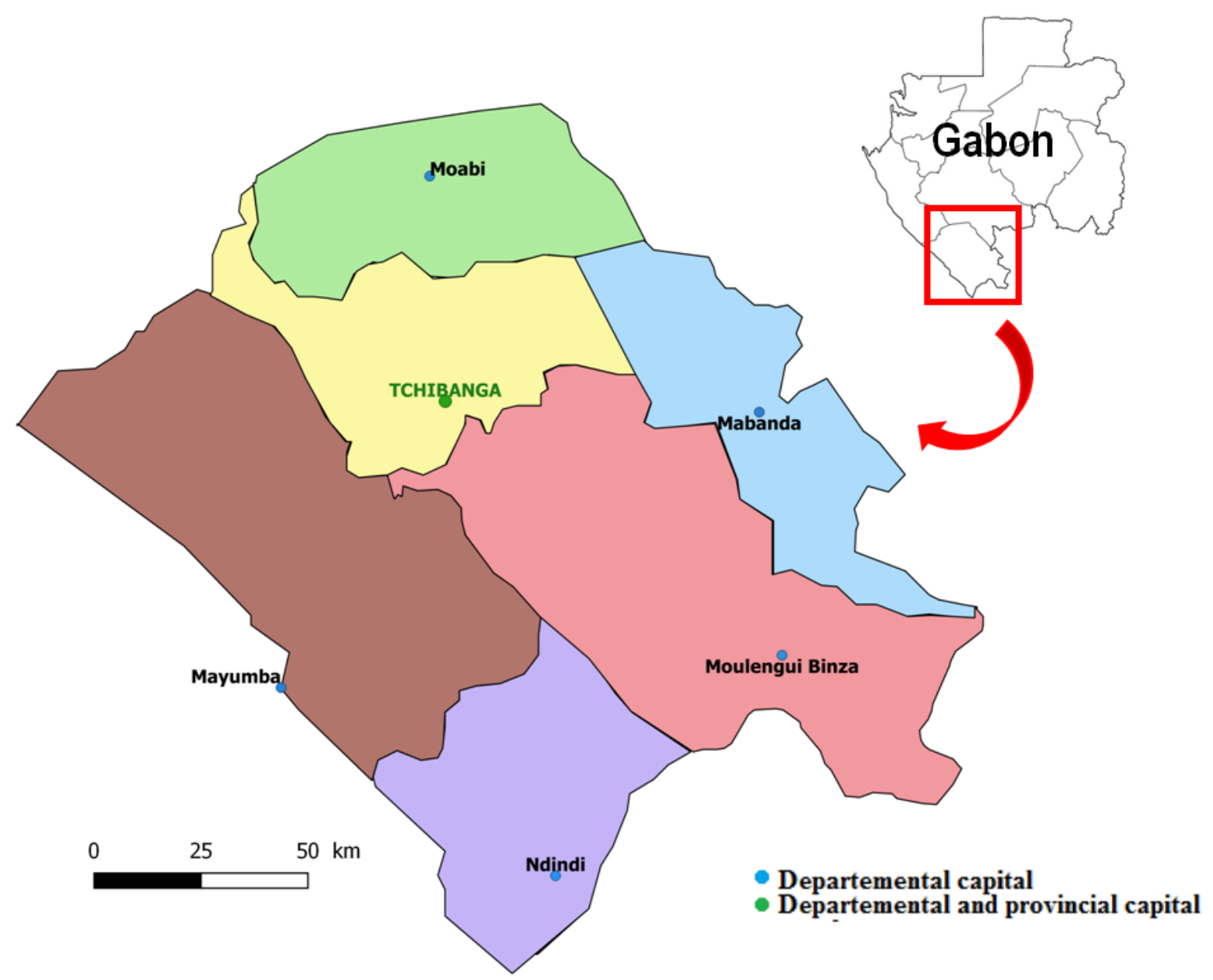

Figure 1 
Map of Gabon's Nyanga province. Shown colors are the six departments with their capitals: Tchibanga (departmental and provincial capital), Moabi, Moulengui-Binza, Mayumba, Mabanda and Ndindi (excluded from the study due to access issues). Note: The designations employed and the presentation of the material on this map do not imply the expression of any opinion whatsoever on the part of Research Square concerning the legal status of any country, territory, city or area or of its authorities, or concerning the delimitation of its frontiers or boundaries. This map has been provided by the authors.

\section{Supplementary Files}

This is a list of supplementary files associated with this preprint. Click to download.

- Additionalfile1questionnaire.docx 